\title{
O Pensamento de Ronald Dworkin Sobre as Ações Afirmativas
}

\author{
Rosaly Bacha Lopes \\ Mestrado pelo Programa de Pós-Graduação em Direito, Políticas Públicas e Desenvolvimento Regional do \\ Centro Universitário do Estado do Pará - Cesupa. Advogada. http://lattes.cnpq.br/8239759720517386. \\ https://orcid.org/0000-0003-2229-5893. rosalybacha@hotmail.com \\ José Claudio Monteiro de Brito Filho \\ Doutor em Direito das Relações Sociais pela PUC/SP. Professor Titular da Universidade da Amazônia. Professor \\ do Programa de Pós-Graduação em Direito da Universidade Federal do Pará. Professor-associado aposentado da \\ Universidade Federal do Pará. Procurador Regional do Trabalho aposentado. \\ http://lattes.cnpq.br/7823839335142794. https://orcid.org/0000-0003-2229-5893. jclaudiobritofilho@gmail.com
}

RESUMO

O objetivo é analisar o pensamento de Ronald Dworkin sobre as ações afirmativas. Para tanto, propôs-se desenvolver questões relacionadas à decisão da Suprema Corte Americana, principalmente no que se refere à leitura feita a partir dos casos Bakke, Weber, Sweatt, DeFunis e Hopwood. A metodologia empregada baseou-se no levantamento de dados secundários colhidos a partir da técnica de documentação indireta, sobre os quais se aplicou o método hermenêutico. Concluiu-se que Dworkin é favorável à discriminação inversa, baseada em problemas históricos, além de favorecer grupos sub-representados que receberam no passado um tratamento injusto.

Palavras-chave: Ações afirmativas. Decisão da Suprema Corte EUA. Dworkin.

\section{THE THOUGHT OF RONALD DWORKIN ON AFFIRMATIVEACTION}

\section{ABSTRACT}

The goal here is to analyze the thinking of Ronald Dworkin on affirmative action. To this end, it was proposed to develop issues related to the decision of the U.S. Supreme Court, especially with regard to reading from the Bakke case, Weber, Sweatt, DeFunis and Hopwood. The methodology used was based on a survey of secondary data collected from indirect documentation technique, which applied the hermeneutical method. It was concluded that Dworkin is in favour of reverse discrimination that is based on historical issues, a form of discrimination that favors underrepresented groups who received unfair treatment in the past.

Keywords: Affirmative actions. US Supreme Court decision. Dworkin.

\section{SUMÁRIO}

1 Introdução. 2 A Justiça ou Injustiça das Cotas. 3 A Decisão no Caso Bakke. 4 A Interpretação da Lei de Direitos Civis. 5 Os Casos Sweatt e DeFunis. 6 O Caso Hopwood e o Estudo River. 7 O Resultado do Estudo River. 8 Conclusão. 9 Referências.

Recebido em: 25/1/2018

Aceito em: $13 / 11 / 2019$ 


\section{INTRODUÇÃO}

O presente artigo objetiva analisar o pensamento de Ronald Dworkin sobre as ações afirmativas. Essa política visa a reduzir as desigualdades sociais, garantindo igualdade de oportunidade no acesso via sistema de cotas nas universidades norte-americanas.

Dworkin (2000) debruça-se sobre as ações afirmativas na sociedade americana, local pioneiro na adoção desta política, cuja instituição deu-se com vistas ao combate à marginalização social e econômica dos negros naquela sociedade. Pensa Dworkin (2000, p. 440) que "somos obrigados a olhar os argumentos a favor da ação afirmativa com solidariedade e espírito aberto".

Para Brito Filho (2014, p. 74), a "justiça das ações afirmativas é uma realidade, desde que tenha por objetivo distribuir melhor os recursos valiosos existentes, promovendo o bem comum".

É inegável, todavia, que o maior efeito devastador dos direitos humanos deu-se no campo da educação, sobretudo devido à discriminação em razão da raça, pois estes grupos vulneráveis são preteridos no acesso à educação de qualidade pela falta de recursos materiais que possibilitam a sua inserção em pé de igualdade com os beneficiários da injustiça perpetrada (BRITO FILHO, 2014, p. 61).

Assim, compreender o direito à educação como direito humano e fundamental é condição sine qua non da situação cidadã, o que resulta em uma vida comunitária que se aproxima dos ideais democráticos de convívio social, com liberdade e uma vida atuante nas decisões políticas (MANTOAN, 2006).

Ademais, tem-se que o Ensino Superior é organizado para atender a um público privilegiado, com um projeto educacional elitista, que prima pelo mérito, de modo a homogeneizar esses alunos selecionados e, com isso, a universidade, ao invés de incluir o ser diferente, vem prejudicando um direito fundamental de muitos estudantes (MANTOAN, 2006).

É discutível, portanto, o acesso ao Ensino Superior, posto que as desigualdades de oportunidades são patentes na sociedade. Isso deve-se à baixa eficiência dos Ensinos Fundamental e Médio públicos, razão pela qual estudantes com poder aquisitivo têm melhor condição de se preparar em uma escola privada e, por conseguinte, serem bem-sucedidos no vestibular (LAUREANO, 2008).

Deve-se registrar, também, conforme observa Brito Filho (2014), que existe no ensino público deficiência na base e, caso não seja adotada pelo Estado medida de correção, "manterão sempre o desnível verificado no grau de instrução das diversas classes sociais e dos grupos que compõem a sociedade" (LAUREANO, 2008, p. 76).

Assim, as desigualdades reais e atuais de oportunidade e de competição no acesso ao Ensino Superior entre os alunos da rede pública e os da rede privada, torna-se sem razão de ser quando são aplicadas políticas afirmativas em relação à parte mais vulnerável. Essa política colabora com a realização da igualdade substantiva (BRITO FILHO, 2014).

Nessas perspectivas, as Universidades em países como o Brasil, em desenvolvimento, apresentam-se como um espaço singular de invento e difusão do saber científico, de sorte que o mercado de trabalho agradece aos profissionais qualificados que recebem. Apresentam-se, 
ainda, como instituições sociais que se compõem do tripé ensino, pesquisa e extensão e, ademais, como aparelhos ideológicos do sistema capitalista, igualmente molas motoras da mudança social e do desenvolvimento (BELTRÃO; BRITO FILHO; MAUÉS, 2016).

É nesse contexto que os direitos sociais e econômicos colocam em xeque a legitimidade do modelo institucional presente, de modo a reclamar a efetivação de direitos sociais conquistados. As instituições precisam, portanto, adaptar-se para responder às questões oportunas na missão de compatibilizar a democratização de ingresso pleiteado pelos direitos sociais (BELTRÃO; BRITO FILHO; MAUÉS, 2016).

As instituições, como molas impulsionadoras de transformação social, precisam apareIhar-se para atender às respostas dos grupos que procuram uma vaga na universidade. Por esta razão, as ações afirmativas são modelos de distribuição dos recursos que reclamam investimentos à instituição para formação de corpo discente diversificado (BELTRÃO; BRITO FILHO; MAUÉS, 2016).

Brito Filho (2014) assevera que as ações afirmativas são uma das formas de medidas, adotadas pelo Estado, com o objetivo de corrigir as desigualdades e, com elas, a exclusão. Para esta empreitada, é necessário observar a sua compatibilidade, vista sobre diversos ângulos.

Para Brito Filho (2014), a ação afirmativa será adotada quando ela for compatível com a correção da desigualdade. De modo contrário, a política afirmativa não será instituída enquanto a redução da desigualdade não for alcançada e, ademais, deve haver a escolha da medida a adotar, dentre as várias possibilidades, como fixação de cotas, benefícios de natureza fiscal ou estímulos, isso porque pertencer a um grupo vulnerável é apenas uma forma de escolha dentre outras possíveis.

Espera-se, portanto, com a ação afirmativa, que integrantes de minorias sejam beneficiados com perspectivas reais de ascensão na hierarquia social e de melhor posicionamento na sociedade. Para Gomes (2001, p. 48), as ações afirmativas podem ser pensadas como um estímulo à educação e "ao aprimoramento de jovens integrantes de grupos minoritários".

O que resta a saber é o pensamento de Ronald Dworkin sobre as ações afirmativas.

Objetiva-se analisar as decisões da Suprema Corte Americana nos Casos Bakke, Weber, Sweatt, DeFunis e Hopwood. Para tanto, serão pesquisadas algumas obras de Dworkin, filósofo contemporâneo de grande prestígio na sociedade americana, nas quais se dedicou à análise da ação afirmativa.

Em breve síntese, o caso Bakke trata da forma de admissão adotada pela Universidade de Medicina da Califórnia, que previa duas vias de seleção, e em uma via reservou 16 das cem vagas ofertadas para membros de grupos "minoritários". Para alcançar uma vaga, porém, esse grupo necessitava de uma média inferior quando comparada com outro grupo que disponha das demais vagas (GOMES, 2001).

Bakke, estudante branco, então, candidatou-se às demais vagas sem sucesso, e teve seu pedido rejeitado, em que pese sua nota ser suficiente para alcançar uma vaga, isso se não fosse estabelecido pela Instituição um programa de cotas em favor de grupos minoritários (GOMES, 2001). 
A metodologia empregada no presente artigo permite toda a análise do que se propõe, e baseia-se no levantamento de dados secundários de acordo com a técnica de documentação indireta, especialmente as obras de Ronald Dworkin, sobre as quais se aplicou o método hermenêutico, considerando que se visa a analisar o pensamento de Ronald Dworkin sobre as ações afirmativas.

\section{A JUSTIÇA OU INJUSTIÇA DAS COTAS}

Na obra "Uma Questão de Princípio", mormente no capítulo 14, Dworkin, expõe o célebre processo Regentes da Universidade da Califórnia $v$. Bakke. O caso trata de um candidato a estudante na faculdade de medicina da Universidade da Califórnia que judicializou sua preterição em benefício de candidatos negros, membros de "minorias em desvantagem educacional e econômica", que obtiveram menor qualificação, contudo foram admitidos em razão do programa de ação afirmativa (chamado de "programa de força-tarefa") instituído pela Universidade (DWORKIN, 2000, p. 437).

A Suprema Corte Norte-Americana, em 1978, julgou o caso, tornando-se uma referência na elucidação do que era ou não permitido nos programas de ações afirmativas instituídos pelas universidades de Ensino Superior. A decisão foi no sentido de que o sistema de ingresso adotado pela Instituição, assentado em cotas rígidas, era ilegal, mas, entretanto, definiu como legítimo o critério racial como meio de seleção de alunos, contanto que esse critério fosse combinado com outro.

Ficou sedimentado, então, que a raça pode ser utilizada como critério de seleção, por servir para reparar a desvantagem acometida aos grupos minoritários em virtude da discriminação sofrida. Ademais, a raça é considerada meio para garantir a diversidade no âmago da Instituição de Ensino Superior, isso porque essa convivência em meio à diversidade contribui para enriquecer essa experiência e, também, cumpre parte do objetivo da universidade.

Para Dworkin (2000, p. 438), os programas de ações afirmativas apresentam como objetivo "aumentar a matrícula de estudantes negros e de outras minorias admitindo que o critério racial conte afirmativamente como parte das razões para admiti-lo".

Os opositores a essa política pública entendem que o programa de ações afirmativas de base racial é um exemplo de discriminação racial contra brancos, classificada como uma representação desacertada, de iniciativas que compreendem um caráter compensatório ou distributivo (MOREIRA, 2013). Ainda, sustentam que com as ações afirmativas acirraria o problema da intolerância racial, por produzir uma forma de discriminação contra a população branca, que raramente discrimina negros (MOREIRA, 2013).

Os opositores do programa de ação afirmativa aduzem que tais programas iriam alcançar uma sociedade racialmente consciente, a qual seria dividida em grupos raciais e étnicos, de maneira que cada grupo atingirá uma parcela proporcional de recursos, carreiras e oportunidades (MOREIRA, 2013). Dworkin afirma que a sociedade norte-americana é uma sociedade racialmente consciente, de modo que essa consciência foi corroborada com uma história de escravidão, repressão e preconceito, refletindo ainda hoje. 


\section{Humanos e}

Democracia

Moreira (2013) aduz que o conceito de racismo está presente no discurso da neutralidade racial, de maneira que apresenta consequência para a interpretação do princípio da igualdade nas decisões judiciais afetas a ações afirmativas. Os defensores sustentam que o racismo é apenas um comportamento individual que se baseia numa falsa representação sobre os membros de outros grupos raciais. Com isso, a verdadeira compreensão é oculta, pelo fato de que diferentes manifestações de racismo caminham em direção à opressão racial sistemática de afrodescendentes (MOREIRA, 2013).

Os programas de ações afirmativas visam a reduzir a importância racial, não obstante utilizar critérios racialmente explícitos, posto que outras mais suaves fracassarão, de modo que seu objetivo imediato é reduzir e não aumentar a importância da raça (MOREIRA, 2013).

Ademais, esses programas estão alicerçados sobre dois juízos: o juízo relacionado à teoria social e o juízo que se baseia no cálculo de estratégia. O primeiro juízo, afirma Dworkin (2000), é que a sociedade continuará imbuída de divisões raciais, de maneira que "as carreiras mais lucrativas, gratificantes e importantes continuarão a ser prerrogativa de membros da raça branca", gerando, com isso, a exclusão de outros de participar de uma elite profissional e social. Em relação ao cálculo de estratégia, considera o autor que o crescimento do número dos negros nas inúmeras profissões tem como consequência, a longo prazo, diminuir a sensação de frustração, injustiça e constrangimento racial presente na população negra (MOREIRA, 2013, p. 439). Do mesmo modo, o autor adverte que a recusa ao programa de ação afirmativa é desprovida de cuidado, tal como é errôneo entender que "combater fogo com fogo ou de que o fim não pode justificar os meios" (MOREIRA, 2013, p. 440).

Adverte, ainda, que refutar o programa com a justificativa que é baseada em testes racialmente explícitos é, portanto, repugnante, de maneira que "Se tais testes são repugnantes, só pode ser por motivos que tornam ainda mais repugnantes as realidades sociais subjacentes que os programas atacam" (DWORKIN, 2000, p. 440).

Dworkin (2000) entende que as incertezas que pairam sobre os resultados dos programas, a longo prazo, não são capazes de justificar uma decisão, tornando o programa ilegal pelo Supremo Tribunal. Por outro lado, pode-se entender que, mesmo sendo eficazes, no sentido de reduzir a importância da raça, os programas, entretanto, são inconstitucionais.

Essa foi a posição assumida na defesa de Bakke. Seu advogado, Colvin, entendeu que o programa violava o direito constitucional de seu cliente. $O$ juiz White indagou Colvin sobre a importância do programa, de modo que reconheceu sua importância, contudo sustentou o direito de Bakke, o qual independe de qualquer julgamento favorável para a sociedade como um todo (DWORKIN, 2000).

A pergunta que se faz, entretanto, é: Bakke tem esse direito como tão importante, de maneira que os objetivos urgentes da ação afirmativa devam ser ignorados? Em resposta, Dworkin (2000, p. 445) aduz que a Constituição não prevê expressamente nenhuma vedação à ação afirmativa, de modo que se Bakke está certo deve ser porque possui, além do direito jurídico técnico, também um importante direito moral.

O argumento levantado em defesa é o de que Bakke possui direito de ser avaliado em harmonia com seu mérito e, ainda, o direito de ser avaliado enquanto indivíduo, o que afasta qualquer avaliação como membro de um grupo social, por ter o direito igual a qualquer 
cidadão negro de não ser preterido em oportunidades em razão de sua raça. Dworkin (2000) entende que os argumentos não passam de expressões capciosas, por resumir sua defesa em único argumento: o de que "ninguém deve sofrer com o preconceito ou o desprezo dos outros". Nesse sentido, o autor responde a cada resposta formulada por Bakke.

Para Dworkin (2000) não há razão para usar, tão somente, o mérito intelectual como critério de admissão na universidade, por inexistir qualquer vedação que impeça a utilização de outro critério, e segue afirmando que não existe uma definição do que seja mérito.

À segunda das expressões capciosas, Dworkin responde que a defesa de Bakke, quando afirma que seu direito está sendo violado em razão de ser avaliado enquanto membro de um grupo, ao invés de ser avaliado enquanto indivíduo, não há razão de ser, uma vez que os processos de admissão contam com generalizações sobre grupos. Dworkin (2000) segue afirmando que existem Universidades que utilizam como teste de seleção a idade, seja para negar ou admitir candidatos, de modo que Bakke teve seu pedido negado em duas outras faculdades de medicina. À vista disso, essas duas Universidades de medicina, que adotam a idade como critério de seleção, violaram o direito de Bakke de ser submetido à avaliação como indivíduo, ao revés, de ser avaliado como membro de um grupo?

Para concluir, Dworkin (2000) entende que esses critérios não negam o direito de Bakke de ser submetido à avaliação como indivíduo, de maneira que essa conclusão também pode ser estendida para o critério racial, por não negar tais direitos. Por fim, a terceira das expressões capciosas foi formulada pelo advogado de Bakke, que afirmou que seu cliente tem o direito de não ter sua vaga rejeitada apenas por causa de sua raça, por ser um direito constitucional. Essa última defesa soa mais plausível quando comparada às duas primeiras, quais sejam: avaliação por mérito ou como indivíduo (DWORKIN, 2000).

Ademais, esse direito constitucional é de importância fundamental, e foi violado por décadas, por exclusões racistas e cotas antissemitas. São de base histórica as exclusões baseadas na raça, motivadas por causa do desprezo que determinadas comunidades sentiam em relação a grupos raciais ou religiões excluídas (DWORKIN, 2000, p. 449).

Para Dworkin (2000, p. 449), é um absurdo a reivindicação de Bakke quando considera que teve negada sua admissão na Universidade de medicina por causa de sua raça, porque no seu caso a "raça não se distingue pelo caráter especial do insulto público", diferente do que ocorre com os negros.

Concluindo, Dworkin (2000, p. 450) afirma que Bakke foi sacrificado em razão de seu baixo nível de inteligência, ou seja, isso não significa que sua rejeição seja por preconceito, "mas por causa de um cálculo racional do uso socialmente mais benéfico de recursos limitados para a educação médica".

Em resposta aos que defendem a não utilização do programa de ação afirmativa, em decorrência das classificações raciais que foram e também podem ser utilizadas com fim maligno, Dworkin (2000, p. 450) esclarece que isso não procede, por ser o "conhecido recurso à preguiçosa virtude da simplicidade. Supõe que se é difícil traçar uma linha ou que, se traçada, ela seria difícil de administrar, é prudente não tentar traçá-la". 
Dworkin (2000) não descarta a possibilidade desses casos, mas isso somente é possível quando, nos fatos em questão, não se tiver grandes perdas como consequência. Dworkin (2000) sustenta, então, que esse argumento não se aplica ao programa de ação afirmativa; isso em razão da grande perda que implica deixar de instituí-la.

\section{A DECISÃO NO CASO BAKKE}

A decisão proferida pelo Supremo Tribunal no caso Bakke foi recebida com alívio por boa parte do público e da imprensa, dado que essa decisão resolveu o debate da forma que as partes pareciam desejar. Essa decisão, para Dworkin (2000), entretanto, carece de justificação.

Bakke moveu uma ação junto ao Poder Judiciário, chegando o caso à instância da Suprema Corte Norte Americana. A decisão do Supremo Tribunal da Califórnia foi procedente a Bakke, de maneira que determinou que a Universidade de medicina o admitisse, e, além disso, vetou a utilização da raça como método de admissão nas Universidades da Califórnia. No mesmo sentido foi a decisão do Supremo Tribunal dos Estados Unidos quanto à admissão de Bakke, que entendeu, de modo diferente, a utilização da raça, e, por isso, revogou a proibição do Tribunal da Califórnia quanto a utilizar a raça sob qualquer circunstância (DWORKIN, 2000).

A linha de defesa de Bakke sustentou que o programa era ilegal consoante previsão da Lei de Direitos Civis de 1964, ao dispor que ninguém "em razão da raça será excluído de participação, será privado dos benefícios ou sujeito a discriminação em qualquer programa". De outro modo, argumentou que o programa era inconstitucional, por negar a igual proteção assegurada na Décima Quarta Emenda (DWORKIN, 2000, p. 453).

A Corte, composta de nove juízes, apresentou três posições diversas. Do universo de nove magistrados, quatro juízes entenderam que o sistema de cotas para ingresso na Universidade violava o direito civil do cidadão, e, em posição diversa, entenderam outros quatros no sentido de justificar a política de ingresso adotada pela Universidade, tendo em vista a necessidade de reparar os efeitos deletérios da discriminação racial presente na atualidade (DWORKIN, 2000). Por fim, o argumento construído pelo nono juiz - Powell - foi a posição que prevaleceu. Powell sustentou em sua decisão que o programa de cotas fixas é inconstitucional, por representar uma recusa à política que se baseia em cotas raciais, de modo que entendeu que as cotas não fixas, aquelas que utilizam a raça apenas como um entre outros critérios para admitir candidato, a exemplo da Universidade de Harvard, são constitucionais (DWORKIN, 2000).

Em suma, a decisão a favor de Bakke prevaleceu, o que lhe garantiu seu direito de ingressar na Universidade de medicina da Califórnia (DWORKIN, 2000). Tendo como base a argumentação sustentada em defesa de Bakke, Dworkin (2000) observa a consciência racista da comunidade norte-americana, produto de uma história marcada pela escravidão, repressão e preconceito, peculiaridade essa que a ação afirmativa objetiva combater. Para Dworkin (2000), faz-se necessário a utilização de critério racial para enfrentar a questão da consciência social de raça, afastando a utilização de meios neutros racialmente.

Bakke contestou a utilização da raça como critério utilizado pela Universidade para ingresso de negros no Ensino Superior, somente quanto ao direito à igualdade, razão pela qual não pode ser declarado inconstitucional pela Suprema Corte. 
O programa de ação afirmativa seria uma medida adotada para enfrentar um problema existente na sociedade como um todo; isso porque a consciência racial tem se mantido forte ao longo do tempo, então essas são as razões que fazem dessa política um programa justo e necessário.

O autor segue afirmando sua aceitação ao programa de ação afirmativa, de modo a defender sua constitucionalidade e sua adoção como meio de promover a distribuição social, tal como seria um mecanismo de promoção de justiça distributiva igualitária, que reconhece os desníveis sociais que assolam os negros na sociedade americana.

Para Brito Filho (2014, p. 32), as ações afirmativas são medidas que visam à inclusão de minorias vulneráveis, proporcionando acesso ao Ensino Superior, o que oportuniza "correção de desequilíbrios na formação educacional: combatem não só a exclusão, mas também a desigualdade".

Segundo Brito Filho (2014), o programa de ação afirmativa é uma estratégia que "pode e deve", no sentido da discriminação por fatores de exclusão. Dentro dessa ideia, a ação afirmativa é uma diretriz com a finalidade de paralisar os obstáculos que impedem o acesso aos bens e oportunidades. Desse modo, tal ação permite que a distribuição dos recursos, presente em dada sociedade, possa ser feita de forma igualitária.

Dworkin (2000), ao se debruçar sobre o caso Bakke, entende que as ações afirmativas não podem ser entendidas como meio de compensação, mas percebe que o correto seria utilizá-la como medida de integração. $O$ autor segue afirmando que o objetivo principal é contribuir positivamente para a integração étnico-racial, cujo proposito seria dar fim à discriminação, viabilizando a atuação de todos nos diversos setores da sociedade. Com a ação afirmativa, o ambiente acadêmico seria enriquecido com ensino pluralista, de maneira que os estudantes seriam preparados para conviver em uma sociedade formada na diversidade.

\section{A INTERPRETAÇÃO DA LEI DE DIREITOS CIVIS}

O caso Weber foi uma decisão importante para os programas de ação afirmativa, por avaliar a sua legalidade no âmbito laboral, dando aos negros vantagens de treinamento para a indústria, beneficiando-lhes diretamente, promovendo um impacto mais rápido sobre a desigualdade racial e econômica (DWORKIN, 2000).

Na fábrica da Kaiser, localizada em Gramercy, no Estado de Louisiana, os negros tinham uma baixa representação, sem funções ou ofícios de destaque no alto escalão da empresa; por essa razão, a Kaiser Aluminum Company firmou um acordo coletivo com o sindicato em defesa dos interesses da categoria de empregados (DWORKIN, 2000).

No programa de treinamento para funções qualificadas seriam contemplados empregados segundo o tempo de contrato de trabalho e, ainda, $50 \%$ das vagas seriam destinadas aos empregados negros, até que o seu percentual do total dos qualificados no quadro de empregados atingisse a proporção de negros na região em que era desenvolvida a atividade produtiva (DWORKIN, 2000).

O critério de antiguidade adotado nesse programa causou inconformismo. Weber, branco, ingressou uma ação ante a Kaiser, fundamentando seu pleito na seção 703(a) do Título VII da Lei de Direitos Civis de 1964. Restava saber, então, se essa lei tornava ilegal o programa da Kaiser (DWORKIN, 2000). 
Na Suprema Corte, cinco juízes entenderam que Weber não tinha razão, pois a cláusula de igualdade perante a lei é dirigida ao Estado, impondo tratamento igual as pessoas; ao revés, essa exigência não se aplica nas relações entre particulares. Assim, é vedado ao Judiciário instituir direitos fundamentais em relações privadas, cabendo ao particular, tão somente, nas relações diante do Estado (DWORKIN, 2000).

Ultrapassando o debate acerca da legalidade do programa ante a Lei de Direitos Civis, dois juízes enfrentaram a questão acerca da viabilidade do programa diferenciado de acesso de negros no treinamento para funções qualificadas de alto escalão na Kaiser e, ainda, a sua constitucionalidade. Dworkin (2000) refere-se ao voto do juiz William J. Brennan, na parte alusiva à Lei dos Direitos Civis, que fundamenta a efetivação do programa de ação afirmativa, cumprindo um papel importante na promoção da igualdade racial na educação, no emprego e, ademais, em outras áreas. Segue afirmando que a ação afirmativa busca, por fim, a discriminação racial, em que negros são sub-representados em postos de qualidade com remuneração inferior (DWORKIN, 2000).

Em relação à decisão de Rehnquist, argumenta que a lei está baseada numa concepção de igualdade, refutando qualquer distinção que use a raça como alicerce. Dworkin (2000, p. 478) critica as duas decisões pela forma de interpretação da lei, quando tenta adivinhar a intenção do Congresso no momento da criação do dispositivo legal, e segue afirmando que a interpretação feita pelo Poder Judiciário não tem subsídio suficiente para descobrir qual o objetivo do Legislativo na hora da elaboração da norma.

Dworkin (2000) considera um bom argumento o levantado por Brennan, e entende que a ação afirmativa não era uma exigência da Lei, nem uma proibição, uma vez que sua ideia é fundamentada a partir de vários argumentos.

Em relação à decisão do juiz William Rehnquist, cabe ao Judiciário decidir pela melhor interpretação, posto que a decisão pautada na moralidade política é a escolha que buscará criar uma sociedade pautada na justiça racial. Essa posição é defendida pelo autor por entender que essa seria a intenção do legislador quando da elaboração da Lei dos Direitos Civis (DWORKIN, 2000).

Os precedentes da Suprema Corte dos EUA, em questões laborais, têm posição favorável à discriminação inversa. Esse entendimento foi confirmado quando do julgamento do famoso caso emblemático Weber, no qual ficou assentada a constitucionalidade de um programa de ação afirmativa instituído por uma empresa privada em ambiente laboral.

A Suprema Corte entendeu que o procedimento adotado pela empresa não fere a cláusula de igual proteção das leis, entendimento extraído da análise dos debates para aprovação da Lei de Direitos Civis de 1964, e concluiu que esse programa foi criado para eliminar modalidades tradicionais de segregação racial.

A decisão também afirmou que a proibição do programa de ação afirmativa não se coadunava com o propósito da lei, razão pela qual rejeitou a inconstitucionalidade sustentada. Sustentou, ainda, que a lei foi criada para servir de estímulo aos empregadores e sindicatos, de modo a reverem as práticas adotadas, eliminando práticas segregacionistas (DWORKIN, 2000).

\section{OS CASOS SWEATT E DEFUNIS}

Dworkin, em sua obra "Levando os Direitos a Sério" (2002), especialmente, no capítulo 9, discorre sobre dois casos que alicerçam sua análise quanto à temática das ações afirmativas. O primeiro caso ocorreu em 1945, quando um negro nomeado Sweatt pretendeu ingres- 
sar na Faculdade de Direito da Universidade do Texas, tendo seu pedido negado em razão de uma Lei Estadual que determinava que apenas brancos tinham direito de frequentar a Universidade. A Suprema Corte manifestou-se no sentido de que a lei violava os direitos garantidos na Décima Quarta Emenda da Constituição dos Estados Unidos da América, que assegurava igual proteção a uma pessoa, de modo que nenhum Estado pode negar aos seus cidadãos igual proteção perante suas leis (DWORKIN, 2002).

O segundo caso ocorreu em 1971, quando um judeu nomeado DeFunis tentou uma vaga na Faculdade de Direito da Universidade de Washington, e teve seu pedido negado, mesmo que suas notas fossem em tal grau elevadas às de candidatos aprovados por pertencer a grupos minoritários. Por essa razão, DeFunis solicitou à Suprema Corte que declarasse que a forma adotada pela Universidade, menos exigente com candidatos que faziam parte de grupos minoritários, violava a Décima Quarta Emenda e, por isso, era inconstitucional (DWORKIN, 2002).

A Faculdade de Direito da Universidade de Washington adotava um procedimento de seleção complexa, de modo a comtemplar diferentes formas de entrada. $O$ ingresso era, então, dividido em dois grupos: o primeiro era selecionado a partir do mérito, enquanto o segundo grupo, composto de candidatos pertencentes a grupos minoritários, era submetido a uma comissão especial formada por um professor de direito negro e um professor branco (DWORKIN, 2002).

No ano em que DeFunis teve seu pedido negado na referida Universidade, uma grande parte dos requerentes de grupos minoritários aceitos tinha médias inferiores àqueles pertencentes ao grupo selecionado a partir do mérito. A Faculdade de Direito reconheceu, então, que os candidatos pertencentes aos grupos minoritários teriam seu pedido deferido, com a mesma média que DeFunis (DWORKIN, 2002). Esse caso dividiu os grupos que, costumeiramente, adotavam posturas liberais. Assim assinala Dworkin (2002, p. 344):

Em tempos passados, os liberais apoiavam três proposições distintas, a saber:

i) que a classificação racial é um mal em si mesma;

ii) que todos têm direito a uma oportunidade educacional proporcional às suas habilidades;

iii) que a ação afirmativa estatal é o remédio adequado para as graves desigualdades existentes na sociedade norte-americana.

Essas três proposições liberais, entretanto, foram substituídas pelo entendimento que ganhou impulso na última década: que os programas mais eficazes de ação estatal são aqueles que dão uma vantagem competitiva aos grupos raciais minoritários. Ocorre que essa opinião sofreu argumentos contrários, como de alguns educadores, que entendiam que cotas favorecidas são ineficazes e, ainda, contraproducentes; isso porque o tratamento prioritário contribui para reforçar um sentimento já presente em muitos negros: o de inferioridade (DWORKIN, 2002).

Outros aduzem que qualquer discriminação positiva contribui para prejudicar os grupos minoritários, fomentando o preconceito, quando diferenciações raciais são toleradas, isso independentemente do seu objetivo. Ademais, os críticos mais sensatos admitem que ainda é muito prematuro para decidir se o tratamento diferenciado resulta em mais mal do que bem. 
Em reforço a essas críticas empíricas, vê-se, desse modo, o argumento moral, segundo o qual, mesmo se a discriminação compensatória realmente beneficia as minorias, também reduz o preconceito em longo prazo, e, ainda assim, é considerada equivocada (DWORKIN, 2002).

As distinções com base em raça são inerentemente injustas, pois violam os direitos individuais como de DeFunis, por não pertencer a grupos favorecidos, de modo a sofrer o mesmo processo de exclusão (DWORKIN, 2002). Do mesmo modo, o autor entende que DeFunis não possui o direito a insistir que a inteligência seja adotada como único critério para a admissão no Ensino Superior, além do que algumas faculdades de direito acabam instituindo políticas mais qualificadas, combinando testes de inteligência com critérios de outro tipo (DWORKIN, 2002).

Defende DeFunis, entretanto, que a raça não seja usada como critério, independentemente de quanto uma classificação racial possa contribuir para o bem-estar da sociedade e, além disso, contribuir positivamente para diminuir a desigualdade social e econômica. A fundamentação de DeFunis é embasada no direito abstrato à igualdade, consoante à Décima Quarta Emenda, que estabelece que nenhum Estado negará a qualquer pessoa a igual proteção perante a lei (DWORKIN, 2002).

Dworkin (2002) entende que não há nada de incoerente entre o direito de um indivíduo à igual proteção e uma política social desejável sob outra perspectiva, de modo que, às vezes, ambas podem entrar em conflito, até mesmo quando o objetivo é tornar a sociedade mais igual em termos gerais.

Para Dworkin (2002), deve-se necessariamente focar a atenção na conceituação do conceito central, que é o direito à igualdade. Partindo dessa compreensão, os cidadãos teriam dois tipos de direito à igualdade: o primeiro é o direito à igual tratamento, "é o direito a igual distribuição de alguma oportunidade, recurso ou encargo", a exemplo do direito a voto igual em uma democracia; e o segundo é o direito ao tratamento como igual, que corresponde ao direito "não de receber a mesma distribuição de algum encargo ou benefício, mas de ser tratado com o mesmo respeito e consideração de qualquer outra pessoa" (DWORKIN, 2002, p. 350).

Dworkin (2002, p. 350) reconhece, então, a importância ao "direito ao tratamento como igual" que, segundo afirma, "é fundamental", à medida que o "direito ao igual tratamento é derivado" para aplicação de uma igualdade afetiva.

Para Dworkin (2002), qualquer critério de seleção adotado pela Universidade colocará alguns candidatos em posição de desvantagem em relação a outros. Ocorre que essa desvantagem não é fator preponderante para impedir a Instituição de adotar tais políticas de admissão, a exemplo do sistema de cotas, de modo que essas políticas representam ganho para a sociedade como um todo.

Nessa situação, qualquer desvantagem resultante da utilização das ações afirmativas pode ser motivada nos casos em que os ganhos auferidos pela política extrapolem a perda daqueles que "sofreram desvantagem", assim como pela ausência de outra política que fomente com o mesmo ganho (DWORKIN, 2002, p. 351). 
Para Dworkin (2002, p. 351), "o direito de um indivíduo de ser tratado como igual significa que sua perda potencial deve ser tratada como uma questão que merece consideração. Mas essa perda pode, não obstante isso, ser compensada pelo ganho da sociedade em geral".

A perda individual de algum candidato, portanto, será compensada por um ganho maior, dado que a sociedade como um todo será beneficiada (DWORKIN, 2002).

Ademais, Dworkin (2002, p. 358) sustenta que "Qualquer sociedade que recorra a essa ideia para justificar uma política discriminatória, vê-se diante de uma série de dificuldades teóricas e práticas". Tal afirmação decorre em razão de existir dois sentidos distintos para afirmar que uma comunidade está ou não melhor como um todo; essa melhora dá-se em um sentido utilitarista ou pode estar melhor em um sentido ideal.

Conforme Dworkin (2002, p. 358), uma sociedade estar melhor em um sentido utilitarista significa afirmar que:

O nível médio ou coletivo do bem-estar comunitário aumentou, apesar de o bem-estar de alguns indivíduos ter diminuído, de outro modo, uma sociedade estar melhor em um sentido ideal quer dizer que é mais justo ou, de algum outro modo, mais próximo de uma sociedade ideal, quer o bem-estar médio seja ou não aumentado.

Segundo Dworkin (2002), os argumentos sustentados pelos utilitaristas apresentam dificuldade especial que não se observa nos argumentos de ideal, pois essa dificuldade resulta em definir o que quer dizer bem-estar médio ou coletivo. Consiste em saber se existe alguma forma de avaliar o bem-estar de um indivíduo, mesmo em princípio, e como os aumentos do bem-estar de diferentes indivíduos podem ser adicionados e, em ato contínuo cotejados às perdas, de maneira a fundamentar a argumentação de que, no final, os ganhos superam as perdas.

Assim, uma política torna uma sociedade melhor consoante posição utilitarista; "se satisfaz o conjunto de preferências melhor do que o fariam as políticas alternativas, ainda que ela não satisfaça as preferências de alguns" (DWORKIN, 2002, p. 359).

Uma leitura sem atenção devida pode levar à conclusão de que o argumento utilitarista na utilização de uma política se justifica quando é capaz de satisfazer um número maior de preferências em termos gerais, seja um argumento igualitário (DWORKIN, 2002).

O caráter igualitário de um argumento utilitarista, entretanto, pode apresentar-se, frequentemente, como enganoso, posto que introduzir certa política pode estar sendo considerado preferências pessoais "pela sua própria fruição de certos bens ou certas oportunidades", em conjunto com as preferências externas, "pela atribuição de bens e oportunidades a outros, ou ambas as coisas" (DWORKIN, 2002, p. 361).

É necessário distinguir as preferências pessoais das preferências externas, pois, caso um argumento utilitarista inclua ambas as preferências, o caráter igualitário presente nesse argumento ficará comprometido (DWORKIN, 2002).

Assim, o critério utilitarista, ao empregar a preferência de um número considerável de pessoas, desconsidera que as escolhas feitas por determinadas pessoas pode se distanciar de seus interesses pessoais, de modo a querer tão somente prejudicar o interesse de outras pessoas, as quais despreza ou tem preconceito, violando direito ao tratamento igualitário. Por essa razão, o critério utilitarista estaria sendo usado para mascarar preconceitos, ao endossar a manutenção do bem-estar da maioria (DWORKIN, 2002). 
Dworkin (2002) entende que o argumento utilitarista é injusto quando apresenta desvantagem para um indivíduo pertencente a uma raça na qual existe preconceito, sendo, portanto, afastado esse entendimento quando a desvantagem persiste, mesmo estando ausente o preconceito.

Para Dworkin (2002), os argumentos do tipo utilitarista ou do tipo ideal são utilizados na adoção de políticas de ações afirmativas.

Dworkin (2002) formula o conceito de igualdade sem desconsiderar a importância da liberdade, de modo que interpreta os princípios da igualdade e da liberdade em conjunto, sem elevar a importância de um em detrimento do outro, considerando-os conjuntamente necessários e dependentes.

Nesse viés, chama atenção Brito Filho (2014), por entender que institui meios para que as pessoas possam usufruir dos bens da vida, o que somente tem razão de ser quando existe liberdade para agir em rumo ao seu destino. Ademais, ressalta que "nada há de valioso em uma vida que a pessoa leva de forma imposta, sem poder explorar suas potencialidades" (DWORKIN, 2002, p. 17).

Além disso, Brito Filho (2014) defende o modelo que foi denominado, por Álvaro de Vita, de liberalismo de princípios, ou de liberalismo kantiano, e Gargarella (2008) nomeia de liberalismo igualitário. Para este autor, as sociedades que acolhem o postulado do liberalismo igualitário e, ainda, pensadas em conjunto com a distribuição de recursos de Dworkin, em acréscimo extraído de Sen, são caminhos para criar condições favoráveis para uma mais justa distribuição de bens e oportunidades, de modo que os indivíduos possam concretizar suas histórias de vida (GARGARELLA, 2008).

Sobressai a concepção contemporânea de justiça distributiva, e apresenta-se, ao mesmo tempo, alicerçada com base na teoria da justiça desenvolvida por John Rawls (2016), denominada justiça como equidade. O referido autor entende que "a justiça é a primeira virtude das instituições sociais" (RAWLS, 2016, p. 3). Partindo dessa premissa, o autor assevera que é irrelevante leis e instituições eficientes e bem organizadas quando lhe falta a justiça, por isso defende que, nesse caso, as instituições devem sem eliminadas. Do mesmo modo, reconhece que nem todo o bem-estar da sociedade é, por consequência, capaz de justificar a violação da liberdade de uma pessoa.

A justiça como equidade, para Rawls (2016), significa que todos estão em uma situação inicial de igualdade, de modo que os princípios, "eles próprios", são resultado de um acordo original em posição inicial de igualdade, ou seja, todos estão numa situação semelhante, portanto a escolha é resultado de um consenso ou ajuste equitativo.

A posição original, apresentada por Rawls, representa uma posição hipotética, que significa o ponto a partir do qual seriam escolhidos os princípios de justiça. Ademais, Rawls (2016) utiliza essa ferramenta, que ele chama de posição inicial, para solidificar quais os princípios que os indivíduos iriam preferir para orientar a estrutura básica da sociedade.

$\mathrm{Na}$ tentativa, portanto, de eleger princípios que mais bem se coadunassem às principais instituições sociais, Rawls (2016) criou um ambiente imaginário, hipotético, que servisse de base para eleger princípios adequados. A partir deste cenário foram criados dois grandes ideais políticos: a liberdade e a igualdade. 
Observa-se que Rawls (2016) adotou uma concepção de justiça que não aceita que um ser humano subjugue outro e, ainda, não tolera a desigualdade que limite a liberdade em prejuízo aos demais, em especial os menos favorecidos.

Ainda, sobre a posição original, a escolha do melhor princípio da justiça dá-se quando as partes são acobertadas pelo véu da ignorância, isto é, "elas não sabem como as várias alternativas irão afetar o seu caso particular, e são obrigadas a avaliar os princípios unicamente com base nas considerações gerais" (RAWLS, 2016, p. 24).

A respeito do véu da ignorância, Gisele Cittadino (2009) entende que esse instrumento garante "a imparcialidade da concepção política de justiça". Isso é possível porque os indivíduos desconhecem sua situação de vida, isto é, não têm conhecimento se são ricos ou pobres, brancos ou negros, doentes ou sadios, a par de outros, o que garante que os princípios escolhidos serão dotados de imparcialidades, tendo em vista que a escolha irá partir desses indivíduos desprendidos de suas experiências individuais (BRITO FILHO, 2014).

Para Rawls (2016), a liberdade precede a igualdade, por representar a forma mais apropriada para atingir a plena realização dos referidos princípios de justiça, o que se verifica na seguinte passagem: "as reivindicações da liberdade devem ser satisfeitas primeiro. Até conseguirmos isso, nenhum outro princípio entra em jogo" (p. 267).

Já para Brito Filho (2014), em que pese a liberdade ser um ideal político fundamental para configuração de uma sociedade democrática, não significa afirmar que esta deve ser vista como uma ordem que antecede a igualdade.

Quando Rawls, em sua justiça como equidade, leva em consideração uma "posição de cidadania igual e os vários níveis de renda e riqueza" (RAWLS, 2016, p. 105), possibilita o acesso de outras posições, como: "diferença de gênero, ou com as decorrentes de castas, de raça ou de etnia", de modo que se torna inaplicável os princípios de justiça (p. 105).

A posição defendida por Rawls (2016) não se harmoniza com a justa distribuição dos recursos ou dos bens primários, expressão utilizada pelo autor, por não considerar fundamental a ideia segundo a qual a diversidade humana por si só é fator de exclusão.

Gargarella (2008) considera que Rawls, ao apresentar sua teoria, desconsidera os dons das pessoas, e estes, por sua vez, podem desencadear uma certa desvantagem de difícil controle. Para melhor compreender, vejamos:

Uma pessoa com salário um pouco maior que a outra, mas com graves afecções físicas, estaria - de acordo com a teoria de Rawls - melhor que esta última, mesmo que seu salário maior não seja suficiente para pagar os remédios que necessita, devido a suas desvantagens naturais (BRITO FILHO, 2014, p. 47).

No mesmo sentido, Dworkin (2002) afirma que o princípio da diferença, da forma que foi concebido por Rawls (2016), não é suscetível satisfatoriamente "à posição das pessoas com deficiências naturais, físicas ou mentais, que não constituem, em si, um grupo em pior situação, pois este é definido economicamente e, portanto, elas não poderiam contar com um representante ou membro médio de tal grupo" (DWORKIN, 2002, p. 107).

Dworkin percebe que Rawls introduz o princípio da reparação com a seguinte definição, "determina que a fim de tratar as pessoas igualitariamente e proporcionar uma genuína igualdade de oportunidade, a sociedade deve mais atenção àqueles com menos dotes inatos e aos oriundos de posições sociais menos favoráveis" (RAWLS, 2016, p. 107-108). 
No capítulo 2 da obra A virtude soberana: a teoria e a prática da igualdade, de Ronald Dworkin (2011), o tema de destaque é o princípio da igualdade. Para o autor americano, o conceito de igualdade está diretamente ligado ao conceito de democracia, de maneira que os cidadãos devem ser tratados com o mesmo respeito e consideração. Ausência de tratamento igualitário pelo Estado, no entanto, apresenta como consequência a não realização da democracia.

Para Dworkin (2002), o ponto culminante que está por trás da igualdade é a forma de tratamento dispensado a todos os indivíduos com a mesma consideração e respeito. Para o autor, formular um conceito de igualdade não é tarefa fácil, de maneira que não basta a utilização da forma "absoluta e indiscriminada".

Segundo Dworkin (2011), a concretização da igual consideração dá-se com a igualdade de recursos. Essa igualdade tem como pressuposto políticas comprometidas com o ideal de igualdade, com distribuição de recursos igualitários a cada indivíduo, de modo que os conceitos de justiça e de responsabilidade individual estão correlacionados (DWORKIN, 2011).

A igualdade de recursos tem como objetivo promover as condições igualitárias de acesso a determinados bens econômicos, sociais e culturais ao longo do tempo, enquanto a igualdade de oportunidades dá início a uma situação de igualdade no momento inicial, chamada pelo autor de "linha de largada"; em seguida, o laissez faire e o livre-jogo do mercado seguem normalmente (DWORKIN, 2011, p. 111).

A teoria da igualdade está apoiada no "princípio da igual importância", que estabelece que toda vida humana merece ser bem-sucedida; em outros termos, que a vida humana "vaIha a pena"; e, na responsabilidade especial, a própria pessoa é responsável pelo seu êxito pessoal, em razão de suas escolhas feitas ao longo da vida, por exemplo as profissionais, de consumo, de estilo de vida dentre outras.

Dworkin (2002) considera que a igualdade absoluta, por ser um valor político fraco, é de fácil combate. $\mathrm{O}$ autor, por ser um filósofo político, tem na igualdade sua maior preocupação. Partindo do conceito de igualdade, torna-se possível determinar os direitos e deveres, razão pela qual a filosofia política está ligada à filosofia do direito.

Para alcançar a melhor métrica de justiça, Dworkin (2011) decide contrapor dois tipos de igualdade: a igualdade de recursos e a igualdade de bem-estar. Inicia com o bem-estar, que nasceu para dar valor aos recursos, de modo que o recurso somente tem valor quando gera bem-estar. Para o autor, a utilização de bem-estar como medida de igualdade é injusto, a exemplo de pessoas com necessidades especiais, que demandam mais recursos para alcançarem o mesmo bem-estar dos demais.

A teoria da igualdade, apresentada por Dworkin (2011), é a igualdade de recursos que estabelece que uma sociedade é justa quando conquista a igualdade de recursos, sendo recursos tudo que os indivíduos possuem individualmente e que sejam capazes de ser trocados ou transferidos. Os recursos são os pessoais ou impessoais: os primeiros estão diretamente ligados ao indivíduo, por isso não são objetos de transferência ou comercialização, como talento, características físicas, mentais e intelectuais, a par de outros, e os recursos impessoais 
são os bens em geral. Então, a igualdade de recursos tem o propósito de igualar os recursos impessoais, e compensar, via seguro hipotético, o diferente nos recursos pessoais, exceto o poder político, que perfaz, também, os recursos públicos.

Dworkin (2011) apresenta a forma como a distribuição igualitária de recursos será ajustada no mercado. Para isso, utilizará uma metáfora dos imigrantes numa ilha deserta com fartos recursos, local onde todos chegaram sem qualquer posse, isto é, todos estão numa mesma condição de igualdade. Os imigrantes chegam à conclusão que precisam dividir igualmente os recursos existentes. Para tal, criam o teste da inveja, no sentido econômico, para averiguar se a distribuição foi realmente igual. Caso concluam que ninguém invejará ou desejará os bens de outra pessoa, a divisão igualitária cumpriu o seu papel (DWORKIN, 2011).

Dworkin propõe um mecanismo de mercado - o leilão - em substituição ao teste de inveja. Todos os imigrantes receberam uma quantidade de conchas (moeda) para adquirirem os bens; os preços serão atribuídos a cada lote, que serão adquiridos por um comprador e todos serão vendidos (DWORKIN, 2011). Para que o leilão seja eficiente, é necessário o princípio da autenticidade e da independência. $O$ primeiro garante a autenticidade da preferência dos imigrantes, sem imposição externa; o princípio da independência prevê que as escolhas são ausentes de preconceitos, e o resultado é uma sociedade sem preconceito e racismo.

Os lances são feitos até o momento em que ninguém inveja a cesta de outrem; caso isso aconteça, a pessoa tem a chance de fazer o lance pelo bem desejado. Aqui, para Dworkin (2011), os custos de oportunidades estão igualados.

Ultrapassado o teste de inveja, que representa a igualdade de tratamento com igual consideração, as diferenças das pessoas são refletidas nos seus bens adquiridos, ou seja, o valor que cada uma atribui à vida, sendo de sua responsabilidade as escolhas feitas.

A teoria da justiça, apresentada por Dworkin (2011), não tem a pretensão de esgotar todas as questões, mas considera a diferença entre os indivíduos, de sorte por opção e sorte bruta. A sorte por opção tem, no princípio do individualismo, responsabilidade especial, quando cada indivíduo responde por suas escolhas de vida, independente se boa ou ruim, e, assim, ninguém deve pagar por escolhas dos outros. Por outro lado, a igualdade de recursos é um "escudo", por nos proteger e basear-se em outro princípio que reconhece que toda vida vale a pena. Por essa razão, devemos ter liberdade no mercado, de modo a escolher o que é mais importante para nosso projeto de vida, isto é, como indivíduos recebermos tratamento como iguais.

\section{O CASO HOPWOOD E O ESTUDO RIVER}

Dworkin (2011) inicia o capítulo 11 da obra A Virtude Soberana: a teoria e a prática da igualdade, com uma pergunta: Ação afirmativa: funciona? Segue afirmando que as melhores universidades e faculdades dos EUA adotaram uma forma de admissão sensível à raça, com o objetivo de expandir o número de alunos pertencentes às minorias.

Desde o seu nascedouro, a política de ação afirmativa foi alvo de ataques por autores e políticos conservadores. Sua existência foi colocada em xeque em 1995, quando a Universidade da Califórnia anunciou que a raça não seria mais contemplada nas admissões da universidade (DWORKIN, 2011). 
A ampliação e a ratificação da proibição deu-se em 1996, com a aprovação do Projeto 209, reconhecendo que nenhuma universidades do Estado pode "discriminar nem oferecer tratamento preferencial a qualquer indivíduo ou grupo com base em raça, sexo, cor, etnia ou nacionalidade no serviço público, educação pública ou contratações públicas" (DWORKIN, 2011, p. 543).

No caso Hopwood v. Estado do Texas, o Quinto Tribunal Itinerante de Apelação declarou inconstitucional a utilização do critério racial na seleção de aluno para formar um corpo discente racialmente diverso da Faculdade de Direito da Universidade do Texas (DWORKIN, 2011).

Os opositores à ação afirmativa destacam que este tipo de ação, ao invés de aliviar a tensão racial, apenas a exacerbou, pois os alunos admitidos apresentaram baixa qualificação, o que contribuiu para o baixo padrão educacional (DWORKIN, 2011).

O estudo The Shape of the River, de William G. Bowen et al. (2016) foi considerado o primeiro exame relevante e estatístico do resultado concreto da ação afirmativa no Ensino Superior dos EUA. Esse estudo debruça-se sobre a base de dados da Faculdade e ACIMA (College and Beyond, C\&B) para analisar a ação afirmativa na educação superior, criado com o propósito de ampliar o ingresso de grupos minoritários, analisando, sobretudo os dados de alunos e formados negros. Todos os dados levantados não foram respondidos, inclusive não teve uma resposta definitiva a questão de os alunos negros, em grupos, apresentarem rendimento baixo quando comparados aos brancos da mesma Universidade; entretanto essas condições não limitam a importância das conclusões do estudo.

Os defensores da ação afirmativa sustentam que uma política é justa quando assegura um bem substancial, beneficiando toda uma comunidade; ao contrário, quando não alcançarem esse fim, então será inútil. Dworkin (2011) aduz que essa política de ingresso à universidade pode ser injusta para aqueles que não alcançaram uma vaga, assim como para o grupo de negros como um todo, mesmo alcançando o resultado pretendido.

Ainda, os que defendem essa forma de política sensível à raça, reconhecem sua importância, no curto prazo, desde que cumpra seu desiderato de erradicar ou diminuir o impacto da raça no longo prazo.

Os críticos, brancos e negros, atacam a ação afirmativa declarando que ela é contraproducente de modo geral, por ter sacrificado, ao invés de ajudar, os negros pertencentes ao programa, em razão da permanência da noção de inferioridade negra entre os brancos e os negros. Isso promove o separatismo negro, motivando uma sociedade separada com relação à raça, ao invés de integrar os negros e promover uma comunidade que é indiferente à cor (DWORKIN, 2011).

Dworkin (2011, p. 549) afirma que a base que sustenta os argumentos a favor e contra são dados superficiais. Os poucos estudos sobre o assunto carecem de profundidade, tornando-se provas frágeis para sustentar grandes declarações. Diferente dos poucos estudos sobre o tema, o The Shape of the River concluiu uma estatística de grande abrangência, com a profundidade necessária de todos os estudos precedentes (DWORKIN, 2011). 
Em que pese o estudo River ser de grande importância, deve-se ter cuidado para não aceitar de forma acrítica. Isso porque falhas podem ser descobertas e, ainda, podem surgir estudos mais profundos que refutem as conclusões de River (DWORKIN, 2011).

Com o estudo de River foi elevado, sobremaneira, o padrão da argumentação, de modo que "qualquer debate respeitável acerca das consequências da ação afirmativa nas universidades precisa agora reconhecer suas descobertas ou refutá-las e qualquer refutação deve estar à altura dos padrões de amplitude e profissionalismo estatístico que Bowen, Bok e seus colegas alcançaram" (DWORKIN, 2011, p. 551).

O estudo concluiu que as exigentes faculdades e universidades obtiveram êxito na aplicação das políticas de ação afirmativa para favorecer metas educacionais importantes a todos (DWORKIN, 2011). Também, mostra que o diploma de uma faculdade seleta não é fator determinante para assegurar uma carreira exitosa, entretanto pode abrir portas, contribuir para a superação de qualquer estereótipo negativo usado pelos empregadores e, ainda, gerar oportunidades (DWORKIN, 2011).

Ademais, o estudo River expressou que a ação afirmativa "também foi inspirada pelo reconhecimento de que o país tinha necessidade premente de negros e hispânicos cultos, que pudessem assumir papéis de lideranças em suas comunidades e em todas as nuanças da vida nacional" (DWORKIN, 2011, p. 559).

Além disso, o estudo River mostra que dobrou o número de negros atuando em instituições de serviço comunitários e, ainda, a grande probabilidade de que negros do sexo masculino adquiram posições de liderança (DWORKIN, 2011).

Essas constatações contribuem para negar o temor de que negros cultos da classe média optariam por viver nova vida afastada da comunidade negra em geral. O temor, portanto, não foi afastado, mas a estatística do estudo é favorável. "O fato de que esse grupo está oferecendo cada vez mais serviços de liderança cívica do que seus equivalentes brancos indica que o compromisso social e as preocupações com a comunidade não foram abandonados ao primeiro sinal de êxito pessoal" (DWORKIN, 2011, p. 559).

Retomemos os opositores que fazem referência às práticas de hostilidade racial no campus e, ainda, atividades como "mesas negras", para induzir que a diversidade racial não foi capaz de reduzir a hostilidade racial, tampouco o isolamento e, inclusive, pode ter contribuído para acentuá-los. De modo previsível, os negros, em maior número do que brancos, reconhecem a importância de conhecer pessoas de outras raças. Essa previsão foi alterada. 0 aumento deu-se em maior percentagem para os brancos (DWORKIN, 2011).

No que se refere ao valor da experiência universitária no autoconhecimento de "se entender" com outros grupos, pertencente a outras raças, o estudo de River apontou duas respostas prováveis: a primeira aduz que pode ter aumentado a consciência da importância da interação entre os alunos, e a segunda traz que pode a universidade ter aderido à ideia que permite gerar um ambiente facilitador dessa interação (DWORKIN, 2011).

Os opositores negros da ação afirmativa revelam que se sentem ofendidos ou prejudicados por essa política por precisarem de favores especiais (DWORKIN, 2011). 
O estudo mostra que os negros estão sub-representados nos cargos de maior prestígio da estratificação social, de maneira que a estratificação racial é uma vergonha que se mantém ao longo do tempo (DWORKIN, 2011).

Faz-se necessário cautela ao concluir pela injustiça da ação afirmativa, isso em razão do baixo dano que essa política inflige a qualquer candidato rejeitado, sejam os brancos e outros candidatos, ou aqueles negros que se sentem ofendidos (DWORKIN, 2011).

O estudo River prescreve que, na hipótese do uso de padrões de neutralidade racial em algumas escolas estudadas, a probabilidade de ingresso dos candidatos brancos excluídos atingiria um percentual de $25 \%$ para $26,5 \%$. Ademais, a declaração de inconstitucionalidade do processo de ingresso da Faculdade de Direito do Texas, pelo Quinto Tribunal Itinerante, e a condenação do quantum devido aos querelantes pela instância inferior, foi de apenas um dólar, por entender a baixa probabilidade de admissão de qualquer rejeitado, apesar de aplicar os padrões de neutralidade racial (DWORKIN, 2011, p. 568).

O que se espera de todas as nossas instituições educacionais, no entanto, é uma postura ativa que promova a ciência, as artes e a filosofia, por ser o progresso responsabilidade pública coletiva, de modo a eleger alunos e professores com esse propósito bem-definido (DWORKIN, 2011, p. 570).

Além do progresso dos conhecimentos como meta a ser alcançada pelas instituições educacionais, espera-se, ainda, que todas as instituições ajudem os alunos e a comunidades de outras maneiras, como dedicar-se ao estudo do tratamento da Aids ou do Mal de Alzheimer. A liberdade acadêmica permite, entre outras coisas, definir metas para si e estratégias acadêmicas, igualmente estratégias de admissão, que entenda ser melhor a essas metas (DWORKIN, 2011).

As notas altas são, tradicionalmente, adotadas pelas escolas em geral, entretanto não se trata de qualificações estritamente acadêmicas como exclusivas, por rejeitarem candidatos com notas altas - inclusive negros -, dando preferência aos alunos com notas mais baixas. Essas qualificações são consideradas na seleção, determinando se o candidato tem perfil para uma ou mais metas costumeiras da Instituição (DWORKIN, 2011).

Ante a essas considerações, em ato contínuo, Dworkin (2011) passa a analisar algumas respostas ao questionamento acerca da injustiça da ação afirmativa, que tem sido levantado por tanta gente.

Inicia pela resposta que sustenta que as políticas de admissão sensíveis à raça, ao julgar os candidatos, não os leva em consideração como indivíduos, mas, tão somente, como membros de grandes grupos; esse, inclusive, foi o argumento sustentado pelo Juiz Powell, quando declarou inconstitucional as primeiras formas, ainda imperfeitas, de ação afirmativa no Caso Bakke (DWORKIN, 2011).

$\mathrm{Na}$ atualidade, a versão da ação afirmativa não considera as cotas; agora é julgado cada caso, com critérios de avaliações abrangentes, o que permite que ninguém seja aceito ou excluído somente em razão da raça (DWORKIN, 2011).

Muitos outros sustentam que a raça, por motivos especiais, não deve ser uma das propriedades entre as qualificações para admissão. Para Dworkin (2011), faz-se necessário distinguir as diversas classificações de raça como especiais e analisar suas consequências. 
O autor inicia com o argumento segundo o qual o critério de admissão sensível à raça exacerba a tensão racial, ao invés de ajudar na sua eliminação; argumento descartado à luz do estudo de River (DWORKIN, 2011). Outros entendem que as classificações raciais, a todo o momento erradas na origem, tenham os resultados desejados. Aduzem, ainda, em tese, que não podemos admitir uso ofensivo da raça para alcançar fins "benignos" (DWORKIN, 2011, p. 574).

O autor refuta esse argumento por entender que formas malignas de discriminação violam direitos individuais, entretanto reconhece que a ação afirmativa bem-elaborada não concorre para isso. Ademais, afirma que é um direito fundamental que cada cidadão tem, inclusive o cidadão negro, de ser tratado pelo governo com igual consideração e respeito (DWORKIN, 2011).

Do mesmo modo, o autor assevera que os defensores da ação afirmativa não exteriorizam preconceito em oposição aos cidadãos brancos, e que não é razoável negar às universidades o poder de atuar ativamente para aumentar a diversidade, a justiça social e a estabilidade, com discurso na suposta possibilidade de que algumas instituições possam afrontar seu poder (DWORKIN, 2011).

Argumenta-se que a história social e constitucional dos Estados Unidos sempre foi motivo de aprisionamento, como povo, por ser uma sociedade indiferente à cor. Nessa perspectiva, a 14ạ emenda de "igual proteção das leis" representou um compromisso assumido pela nação, tanto na seara moral quanto na jurídica, de rejeição à raça. Assim sendo, a ação afirmativa está equivocada, violando ou não os direitos individuais de qualquer pessoa, por não levar em consideração um compromisso nacional importante (DWORKIN, 2011).

Para Dworkin, esse argumento, apesar da sua divulgação, não é convincente. Partes dos críticos da ação afirmativa asseguram que a decisão arguida no compromisso de indiferença à cor seria uma decisão estratégica, e que evitar qualquer classificação racial, em futuro distante, seria plausível pelo resultado alcançado pelo enfrentamento e eliminação do racismo, mesmo que, para isso, pareça, no curto prazo, eficaz em oposição ao racismo, sem oferecer um argumento para essa hipótese estratégica, demonstrada pelo estudo River, que é falsa (DWORKIN, 2011).

A 14ạ emenda não faz referência à raça e, ainda, o resultado de sua interpretação não entende que devam ser excluídas, automaticamente, classificações que levem em conta a raça como meio para alcançar mais justiça. Então, o suposto compromisso da nação americana é uma ilusão (DWORKIN, 2011).

Baseada nas melhores provas alcançadas até o momento, a ação não é contraproducente; ao contrário, aparenta ser bem-sucedida. Nem ao menos é injusta, por não infringir os direitos individuais nem imiscuir-se em nenhum princípio moral (DWORKIN, 2011).

Para Dworkin (2011, p. 578), a discriminação racial do passado refletiu negativamente na nação, pois os cargos de poder e prestígio fizeram parte de uma só raça.

Quando os opositores sustentaram que a ação afirmativa faria mais mal do que bem, essa atitude deu-se pela incerteza que pairava quanto as suas consequências. Esse discurso, entretanto, não tem mais razão de ser; isso em virtude do resultado das estatísticas e análises abrangentes, que demonstrou, de maneira positiva, o seu valor, e, por fim, não temos razão para proibir a ação afirmativa (DWORKIN, 2011). 


\section{RESULTADO DO ESTUDO RIVER}

Dworkin inicia o capítulo 12 da obra $A$ virtude soberana: a teoria e a prática da igualdade com a pergunta: Ação afirmativa: é justa?

No caso Bakke, julgado pela Suprema Corte em 1978, Powell manifestou, em seu parecer, que as preferências raciais são aceitáveis quando seu objetivo for aumentar a diversidade racial entre os alunos, e desde que não sejam adotadas cotas fixas para as minorias, entretanto seja considerada a raça como um dos inúmeros fatores. Dos nove juízes, quatro do referido processo aprovaram o sistema de cotas, enquanto cinco juízes admitiram a constitucionalidade do plano que se coadunava ao disposto nos requisitos de Powell (DWORKIN, 2011).

O estudo River, ao se debruçar sobre uma grande base de dados composta por fichas e históricos dos alunos, obteve um suporte necessário para refutar as afirmativas dos críticos, comprovando o contrário (DWORKIN, 2011). Da mesma forma, esse estudo alcançou um resultado positivo acerca da ação afirmativa, concluindo que ela alcançou um êxito impressionante, de maneira que a ação afirmativa promoveu "notas altas entre alunos de formatura, entre alunos universitários negros, mais líderes negros na indústria, nas profissões, na comunidade e nos serviços comunitários", do mesmo modo que produziu entre as raças um conviver e amizade contínua, o que não seria possível (DWORKIN, 2011, p. 583).

Ainda sobre o estudo, confirmou que se a corte entender pela inconstitucionalidade da ação afirmativa, a presença de negros nas universidades e nas faculdades de elite cairá bastante e, ainda, aduz que será pouco provável o ingresso de negros pelas faculdades de Direito e Medicina; isso, portanto, representa um enorme fracasso para a harmonia e a justiça raciais (DWORKIN, 2011).

Para Dworkin (2011), deve ser afastada a ideia de transgressão à cláusula da igual proteção quando um determinado grupo não tem atendida uma pretensão meritória ou via política, entretanto a violação dá-se quando essa perda for resultado de sua "vulnerabilidade especial ao preconceito, à hostilidade ou aos estereótipos e à sua consequente situação diminuída - cidadania de segunda classe - na comunidade política" (DWORKIN, 2011, p. 584). 0 autor ainda aduz que a supracitada cláusula não é aplicada no sentido de assegura que todos os cidadãos serão beneficiados igualmente em todas as decisões emanadas do poder político. Garante, todavia, tão somente o tratamento igualitário, com igual consideração e respeito em todos os seguimentos resultantes de deliberações e processos políticos.

Dworkin (2011) afirma que a 14a Emenda não prevê expressamente a raça, de modo que não seria razoável pensar que aqueles que a elaboraram e aprovaram teriam a pretensão de proibir integramente todas as classificações raciais. Um quórum considerável votou e aprovou várias classificações raciais, dentre as quais exprimia até a segregação racial em escolas públicas.

Em ato contínuo, o autor segue afirmando que a cláusula de igual proteção requer que seus intérpretes modernos, quando de sua análise, expressem juízos morais, para que possa se manter vivo o princípio geral de moralidade política, determinado por aqueles (DWORKIN, 2011). 
Dworkin (2011) reconhece que o princípio de Bakke está em vigor há cerca de 20 anos, e segue sendo uma lei constitucional boa. Por exteriorizar confiança, as faculdades e universidades podem continuar adotando esse princípio para justificar sua adoção aos critérios raciais de admissão, que asseguram diversidade no corpo discente.

Dworkin (2011) não afasta outro interesse institucional, por ser importante para zelar pelo critério que mantém a raça, como mecanismo que busca corrigir a ainda "deplorável ausência de negros nos principais cargos do governo, da política, das empresas e das profissões" (p. 601).

Para Dworkin (2011), não serve a justiça compensatória como fundamento da ação afirmativa, por defender que essa ação é necessária para "compensar as minorias pelos danos a sua raça ou classe no passado", por entender que uma raça não "deve" compensar a outra. As universidades não adotam essa justificativa para compensar indivíduos nem grupos, pois essa admissão sensível à raça é voltada para o futuro, e não retroage, e "os alunos minoritários a quem ela beneficia não foram, obrigatoriamente, vítimas individuais, de nenhuma injustiça no passado" (p. 606).

$\mathrm{O}$ autor segue afirmando que as grandes universidades, quando se propõem a formar mais discentes negros e outras minorias, busca, com essa educação, não compensá-los por injustiças passadas, mas oportunizar um futuro que represente o respeito às diversidades, quando todos serão beneficiados, contribuindo para acabar com a "maldição que o passado deixou sobre todos nós" (DWORKIN, 2011, p. 606).

\section{CONCLUSÃO}

Os Estados Unidos foi considerado o país pioneiro na introdução dessa política afirmativa, tendo como objetivo o combate à discriminação e ao preconceito, causadores da marginalização social e econômica dos negros na sociedade norte-americana.

Quando se questiona que a ação afirmativa é violadora de direito por desconsiderar as qualificações individuais daqueles candidatos rejeitados, deve-se considerar que a concorrência por vagas na universidade é uma competição que deve tentar selecionar um corpo discente que contribua positivamente às metas legítimas que a instituição estabeleceu (DWORKIN, 2011).

A educação, especialmente a superior, é uma realidade de poucos. Diante disso, torna-se um recurso valioso e escasso. Não obstante ser elitista, as universidades, inclusive "particulares", são pagas por toda a comunidade. Por essa razão, têm responsabilidade pública, que ultrapassa seus próprios corpos docente e discente, devendo beneficiar, via metas, uma comunidade muito mais abrangente (DWORKIN, 2011).

O estudo River atesta que as escolas americanas desejam formar turmas de alunos que apresentem diversidades em vários prismas, por entenderem que contribuirão para a vida profissional e comercial e, inclusive, poderão conduzir-se na vida como bons cidadãos em uma democracia plural, que respeita a diversidade. 
Os Estados Unidos ainda se utiliza da codificação pela cor para praticar os piores estereótipos, desconfianças, temores e ódios. Em razão disso, é indispensável que os negros e os brancos "se conheçam e se admirem, e se alguns negros não tiverem a classe, a cultura ou outras características que Ihes sejam associadas por estereótipos, é obvio que isso aumenta, em vez de destruir, as vantagens da diversidade racial" (DWORKIN, 2011, p. 572).

As escolas, com o propósito de ajudar a melhorar a vida da comunidade, aprimorando sua cultura e sua ciência, entre outras, também ajuda a tornar real essa vida coletiva mais justa e harmoniosa. Elas pensam a segregação como inimiga da justiça e da harmonia e, ademais, reconhecem que a ação afirmativa "começou a erodir tal segregação de um modo que talvez nenhum outro plano ou política poderia fazer" (DWORKIN, 2011, p. 572).

A discriminação racial exterioriza desprezo, e, do mesmo modo, é altamente injusta e prejudicial por condenar uma pessoa pelas características naturais; é, acima de tudo, destruidora da vida de seu paciente. Dworkin (2011) apresenta a cláusula da igual proteção, a qual cumpre um papel importante na proteção dos cidadãos em oposição a todas as discriminações ou classificações jurídicas que Ihe atribua desigualdade.

Entende Dworkin (2011) que o governo é responsável pelas decisões que afetam a vida das pessoas, no sentido de dar direção ao destino e à sorte de cada cidadão. Essas decisões deveriam atender o interesse geral de toda a comunidade, mesmo que para isso beneficiasse uma parte dos cidadãos e prejudicasse outros. Ademais, o autor aduz que não há razão para as classificações raciais serem apontadas como inconstitucionais, pois elas não são moralmente inadequadas (DWORKIN, 2011).

O estudo River aponta duas finalidades pelas quais os exames de admissão sensíveis à raça se justificam: a universidade deve possuir um corpo discente diversificado, atendendo à diversidade racial; e a comunidade tem a necessidade de ampliar a presença dos membros das minorias nas diversas áreas de poder (DWORKIN, 2011).

O estudo River afirma que para alcançar a diversidade racial faz-se necessário utilizar meios eficientes, o que afasta sua fundamentação na classe econômica como representante. O critério racial é considerado eficiente para produzir a diversidade nas diferentes áreas de atuação profissional existentes na sociedade (DWORKIN, 2011).

Para Dworkin (2011), a promoção da diversidade racial no acesso ao ensino superior é um meio adequado utilizado pelas universidades para promover a diversidade racial nas profissões. Para além disto, também considera oportuna a convivência e o relacionamento entre alunos de diferentes traços culturais, pelo que a sociedade teria muito a ganhar com a troca de conhecimentos e saberes.

\section{REFERÊNCIAS}

BRITO FILHO, José Claudio Monteiro de. Ações afirmativas. São Paulo: LTR, 2014.

BELTRÃO, Jane Felipe; BRITO FILHO, José Claudio Monteiro de; MAUÉS, Antonio Gomes Moreira. Ações afirmativas na Universidade Federal do Pará. Revista Inclusiones, v. 3, p. 78-101, 2016.

BOWEN, William G. et al. The Shape of the River: Long-Term Consequences of Considering Race in College and University Admissions. With a New introduction by the autors. Ed. Princeton University Press, 2016.

CITTADINO, Gisele. Pluralismo, direito e justiça distributiva: elementos de filosofia constitucional contemporânea. 4. ed. Rio de Janeiro: Lumen Juris, 2009.

DWORKIN, Ronald. Uma questão de princípio. Tradução Luis Carlos Borges. São Paulo: Martins Fontes, 2000. 
DWORKIN, Ronald. Levando os direitos a sério. Tradução Nelson Boeira. São Paulo: Martins Fontes, 2002.

DWORKIN, Ronald. A virtude soberana: a teoria e a prática da igualdade. Tradução Jussara Simões. 2. ed. São Paulo: Martins Fontes, 2011.

GARGARELLA, Roberto. As teorias da justiça depois de Rawls: um breve manual de filosofia política. Tradução Alonso Reis Freire. São Paulo: Martins Fontes, 2008.

GOMES, Joaquim B. Barbosa. Ação afirmativa \& princípio constitucional da igualdade: o direito como instrumento de transformação social. A experiência dos EUA. Rio de Janeiro: Renovar, 2001.

LAUREANO, Nathalie Albieri. Ação afirmativa e o princípio da igualdade: uma análise constitucional. Brasília, 2008. Concurso ESMPU de Monografia. 10 lugar na categoria estudantes de Graduação.

MANTOAN, Maria Tereza Eglér. O direito de ser, sendo diferente, na escola. In: RODRIGUES, David (org.). Inclusão e educação: doze olhares sobre a educação inclusiva. São Paulo: Summus, 2006. p. 184-209.

MOREIRA, Adilson José. O mito da inocência branca no debate brasileiro sobre ações afirmativas. In: JUBILUT, Liliane Lyra; BAHIA, Alexandre Gustavo Melo Franco; MAGALHÃES, José Luiz Quadros de. Direito à diferença: aspectos de proteção específica às minorias e aos grupos vulneráveis. São Paulo: Saraiva, 2013. p. 61-91. Vol. 2. RAWLS, John. Uma teoria da justiça. 2. ed. Tradução Almiro Pisetta e Lenita Maria Rímoli Esteves. São Paulo: Martins Fontes, 2016.

SEN, Amartya. Desigualdade reexaminada. Trad. Ricardo Doninelli Mendes. Rio de Janeiro: Record, 2001. 